\title{
Identification of genetic loci associated with major agronomic traits of wheat (Triticum aestivum L.) based on genome- wide association analysis
}

Woo Joo Jung ${ }^{1}$, Yong Jin Lee ${ }^{2}$, Chon-Sik Kang ${ }^{3}$ and Yong Weon Seo ${ }^{1,2^{*}}$

\begin{abstract}
Background: Bread wheat (Triticum aestivum L.) is one of the most widely consumed cereal crops, but its complex genome makes it difficult to investigate the genetic effect on important agronomic traits. Genome-wide association (GWA) analysis is a useful method to identify genetic loci controlling complex phenotypic traits. With the RNAsequencing based gene expression analysis, putative candidate genes governing important agronomic trait can be suggested and also molecular markers can be developed.

Results: We observed major quantitative agronomic traits of wheat; the winter survival rate (WSR), days to heading $(D T H)$, days to maturity (DTM), stem length (SL), spike length (SPL), awn length (AL), liter weight (LW), thousand kernel weight (TKW), and the number of seeds per spike (SPS), of 287 wheat accessions from diverse country origins. A significant correlation was observed between the observed traits, and the wheat genotypes were divided into three subpopulations according to the population structure analysis. The best linear unbiased prediction (BLUP) values of the genotypic effect for each trait under different environments were predicted, and these were used for GWA analysis based on a mixed linear model (MLM). A total of 254 highly significant marker-trait associations (MTAs) were identified, and 28 candidate genes closely located to the significant markers were predicted by searching the wheat reference genome and RNAseq data. Further, it was shown that the phenotypic traits were significantly affected by the accumulation of favorable or unfavorable alleles.
\end{abstract}

Conclusions: From this study, newly identified MTA and putative agronomically useful genes will help to study molecular mechanism of each phenotypic trait. Further, the agronomically favorable alleles found in this study can be used to develop wheats with superior agronomic traits.

Keywords: Bread wheat, Agronomic trait, Winter survival, GWAS

\footnotetext{
* Correspondence: seoag@korea.ac.kr

'Department of Plant Biotechnology, Korea University, Seoul 02841, South Korea

2Department of Biotechnology, Korea University, Seoul 02841, South Korea Full list of author information is available at the end of the article
}

(c) The Author(s). 2021 Open Access This article is licensed under a Creative Commons Attribution 4.0 International License, which permits use, sharing, adaptation, distribution and reproduction in any medium or format, as long as you give appropriate credit to the original author(s) and the source, provide a link to the Creative Commons licence, and indicate if changes were made. The images or other third party material in this article are included in the article's Creative Commons licence, unless indicated otherwise in a credit line to the material. If material is not included in the article's Creative Commons licence and your intended use is not permitted by statutory regulation or exceeds the permitted use, you will need to obtain permission directly from the copyright holder. To view a copy of this licence, visit http://creativecommons.org/licenses/by/4.0/. The Creative Commons Public Domain Dedication waiver (http://creativecommons.org/publicdomain/zero/1.0/) applies to the data made available in this article, unless otherwise stated in a credit line to the data. 


\section{Background}

Bread wheat (Triticum aestivum L.) is one of the most widely consumed cereal crops worldwide, providing approximately $30 \%$ of dietary energy to humans [1]. Since the first cultivation of wheat about 10,000 years ago, it has spread over all continents, a fact which has primarily been attributed to its wide adaptability to diverse environments [2]. Furthermore, the development of plant breeding contributed to the success of wheat after the Mendelian genetic law was confirmed in 1900. In particular, the "Green Revolution" between 1965 and 1985 drastically increased the wheat yield by introducing high-yielding semi-dwarf wheat varieties [3]. The yield of winter wheat in the US in 2020 was $3.42 \mathrm{t} / \mathrm{ha}$, which is almost twice that from 50 years ago [4].

While conventional breeding is dependent on selecting superior varieties by phenotyping, more recently, with the development of sequencing technology, molecular breeding began to utilize genetic diversity among varieties. A number of molecular markers such as simple sequence repeat (SSR), random amplified polymorphic DNA (RAPD), and restriction fragment length polymorphism (RFLP) have been utilized in plant breeding [5-7]. However, since the cost of next-generation sequencing (NGS) has begun to decrease, single nucleotide polymorphisms (SNPs) are now becoming the most frequently used marker, owing to their abundance throughout all plant species [8].

Genome-wide association selection (GWAS) is a useful method for identifying candidate genes explaining phenotypic traits by testing the association between the marker type and the phenotype of individuals in a population [9]. As a genotyping tool for GWAS, genotypingby-sequencing (GBS) is one of the popular methods, and array-based and NGS-based platforms for genome-wide high-throughput genotyping have been developed for a number of crops, such as maize [10], rice [11], and barley [12]. For wheat, several SNP genotyping arrays have been developed, including the $9 \mathrm{~K}$ [13], $15 \mathrm{~K}$ [14], $35 \mathrm{~K}$ [15], and $90 \mathrm{~K}[16]$ arrays. Among them, the $90 \mathrm{~K}$ iSelect

Table 1 Basic statistics of the phenotypic variations observed for nine quantitative traits

\begin{tabular}{|c|c|c|c|c|c|c|c|c|c|}
\hline Trait & Environment $^{a}$ & Genotype & Mean & SD & Min. & Max. & Median & CV & $H^{2}$ \\
\hline \multirow[t]{2}{*}{ Winter survival rate (0: 0-10\% to 9: 90-100\%) } & E1 & 287 & 4.171 & 2.796 & 0 & 9 & 4.500 & 0.670 & $\overline{0.606}$ \\
\hline & E2 & 287 & 4.681 & 2.370 & 0 & 9 & 5.000 & 0.506 & \\
\hline \multirow[t]{3}{*}{ Days to heading } & E1 & 260 & 214.8 & 2.904 & 204.0 & 218.0 & 216.0 & 0.014 & 0.848 \\
\hline & E3 & 188 & 189.3 & 2.136 & 181.0 & 195.0 & 189.0 & 0.011 & \\
\hline & E4 & 188 & 180.1 & 4.056 & 168.0 & 188.0 & 180.0 & 0.023 & \\
\hline \multirow[t]{3}{*}{ Days to maturity } & E1 & 135 & 253.0 & 1.789 & 249.0 & 258.0 & 253.0 & 0.007 & 0.815 \\
\hline & E3 & 188 & 224.4 & 2.292 & 219.0 & 230.0 & 224.0 & 0.010 & \\
\hline & E4 & 188 & 217 & 2.904 & 209 & 222 & 217 & 0.013 & \\
\hline \multirow[t]{4}{*}{ Stem length $(\mathrm{cm})$} & E1 & 260 & 77.96 & 15.288 & 40.00 & 122.70 & 74.55 & 0.196 & 0.632 \\
\hline & E2 & 249 & 82.540 & 10.432 & 50.700 & 107.300 & 82.700 & 0.126 & \\
\hline & E3 & 188 & 77.7 & 9.763 & 51.0 & 106.0 & 77.0 & 0.126 & \\
\hline & E4 & 188 & 88.09 & 12.085 & 56.00 & 123.00 & 86.50 & 0.137 & \\
\hline \multirow[t]{4}{*}{ Spike length (cm) } & E1 & 259 & 9.449 & 1.723 & 6.000 & 14.300 & 9.500 & 0.182 & 0.773 \\
\hline & E2 & 249 & 9.116 & 1.430 & 3.300 & 13.000 & 9.000 & 0.157 & \\
\hline & E3 & 188 & 8.974 & 1.023 & 5.900 & 12.000 & 9.000 & 0.114 & \\
\hline & E4 & 188 & 8.719 & 1.060 & 5.500 & 11.800 & 8.700 & 0.122 & \\
\hline \multirow[t]{4}{*}{ Awn length $(\mathrm{cm})$} & E1 & 258 & 5.718 & 1.806 & 0.000 & 9.700 & 5.900 & 0.316 & 0.375 \\
\hline & E2 & 249 & 5.286 & 1.550 & 0.000 & 9.800 & 5.500 & 0.293 & \\
\hline & E3 & 188 & 4.915 & 1.675 & 0.000 & 8.300 & 5.100 & 0.341 & \\
\hline & E4 & 182 & 4.729 & 1.479 & 0.500 & 9.100 & 4.800 & 0.313 & \\
\hline \multirow[t]{2}{*}{ Liter weight (g) } & E1 & 255 & 825.600 & 53.909 & 460.000 & 960.000 & 828.000 & 0.065 & 0.051 \\
\hline & E3 & 188 & 789.7 & 19.648 & 731.0 & 833.0 & 793.0 & 0.025 & \\
\hline \multirow[t]{2}{*}{ Thousand kernel weight (g) } & E1 & 269 & 37.830 & 5.952 & 24.000 & 54.000 & 37.800 & 0.157 & 0.641 \\
\hline & E3 & 188 & 41.65 & 4.180 & 30.90 & 53.30 & 41.70 & 0.100 & \\
\hline \multirow[t]{2}{*}{ Number of seeds per spike } & E1 & 169 & 52.770 & 13.283 & 26.300 & 91.300 & 52.300 & 0.252 & 0.421 \\
\hline & E3 & 188 & 35.27 & 5.731 & 15.00 & 51.00 & 36.00 & 0.163 & \\
\hline
\end{tabular}

${ }^{a}$ E1: Deokso in 2018-2019 season, E2: Deokso in 2019-2020 season, E3: Jeonju in 2018-2019 season, E4: Jinju in 2018-2019 season 
SNP genotyping array, which was developed using 19 bread wheats and 18 durum wheats, is one of the most reliable and widely used tools, and a number of SNPs related to important agronomic traits, such as kernel size [17], grain yield [18], and spike related traits [19], have been identified using the array. Furthermore, with the recent announcement of the wheat reference genome [20], the functional annotation of the genes located near each SNP has become available.

In this study, we observed nine phenotypic traits of 287 wheat accessions from diverse origins in different environments. The phenotypic data were statistically analyzed, and the relationship between each trait was elucidated. Genotyping of the wheat accessions was performed using the wheat $90 \mathrm{~K}$ iSelect SNP genotyping array, and GWA was analyzed. From the GWA analysis, a number of significant genetic loci related to phenotypic traits and candidate genes were suggested, which will be helpful in developing agronomic traits-fortified wheats.

\section{Results}

Phenotypic data and correlation analysis

A total of nine agronomic traits of 287 wheat lines were observed in two to four different environments and analyzed (Additional file 2: Fig. S1 and Table 1). It was observed that WSR had the largest variation while DTH and DTM had the smallest variation among the genotypes based on the $\mathrm{CV} . \mathrm{H}^{2}$ ranged between 0.051 and 0.848 in which LW and DTH had the smallest and largest values, respectively. From the ANOVA analysis (Additional file 3: Table S2), it was revealed that significant differences were present among the genotypes $(p<$ $0.0001)$ and the environments affected these traits (Genotype * Environment $p<0.0001$ ). The Pearson's correlation coefficient between each observed trait's BLUP, except for WSR, was calculated (Fig. 1). DTH was positively correlated with DTM, SL, SPL, AL, and SPS, and DTM was positively correlated with SPL and SPS. A positive correlation was also observed between SPL and AL, TKW, and SPS, and between AL and TKW, while a negative correlation was observed between SL and SPS, and between LW and SPS.

\section{Genome-wide distribution of SNP markers}

Of the 81,587 SNP markers from the wheat $90 \mathrm{~K}$ iSelect array used in the genotyping, 30,218 remained after removing the markers with minor allele frequency $<0.05$ and missing data $>10 \%$ (Additional file 4: Table S3). The SNPs were distributed on all the chromosomes, with 5496; 5853; 3984; 2565; 4313; 3935; and 3900 on chromosomes 1-7, respectively. A total of 172 SNPs were

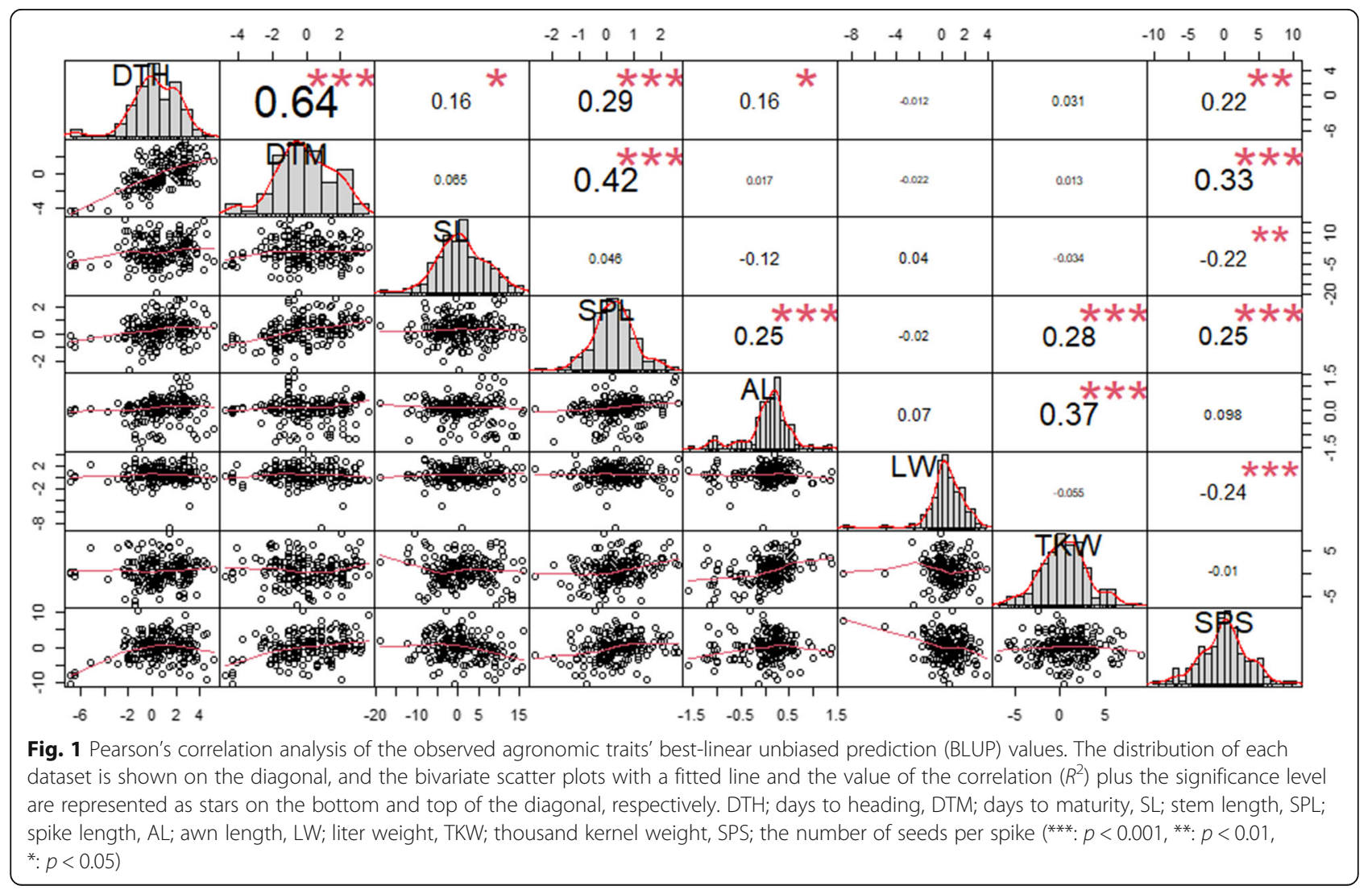


not physically mapped onto the wheat reference sequence. When comparing the subgenomes, the markers were mostly positioned on the A and B genomes, with 13,408 and 12,629, respectively, whereas only 4009 markers were located on the D genome. The range of the locations of the markers on the chromosomes was diverse, with the smallest for 1D from 31.5 to $498,397 \mathrm{~kb}$ and the largest for 3B from 240.2 to $851,642 \mathrm{~kb}$.

\section{Population structure and linkage disequilibrium (LD)}

The population structure of the 287 wheat genotypes was investigated following the $\Delta \mathrm{K}$ method, followed by validation via PCA and neighbor-joining kinship matrix analysis. The outcomes of the three analyses indicated that the genotypes could be divided into three subgroups based on their genotypes (Fig. 2 and Additional file 1: Table S1). The largest group (G1) contained 168 genotypes, and G2 and G3 consisted of 72 and 46 genotypes, respectively. The wheat genotypes derived from the same country of origin were usually in the same subgroup. The wheats originating from Australia, Austria, Bulgaria, Canada, Ethiopia, Hungary, India, Ukraine, and Uzbekistan belonged to G1, while those from Afghanistan, Argentina, Colombia, and Russia belonged to G2. Some of the wheats that came from China, Japan, Mexico, North Korea, and the USA were in both G1 and G2. The Korean breeding lines were divided into three subgroups, but those with "Keumgang" wheat as an ancestor mostly belonged to G3.
From the LD decay analysis, critical $\mathrm{r}^{2}$ value 0.34 was identified for all wheat genotypes by taking the 95th percentile of the coefficient square (represented by the red dashed line in Additional file 9: Fig. S4). The highest number of pair-markers were found on the A genome (44\%) followed by the B genome (42\%) and the D genome (14\%). It was observed that LD decay distance in D chromosome was longer than that of A and B chromosome as shown in Fig. S4. The LD decay was constructed using chromosomal distance and the critical $r^{2}$ value as the threshold to indicate the LD decay length, which attained $250 \mathrm{~kb}$ for the whole genome.

\section{Genome-wide association and gene expression analysis}

The MTAs of nine agronomic traits were identified via MLM with $\mathrm{K}+\mathrm{Q}$ or $\mathrm{K}+\mathrm{P}$, followed by inspection of Q$\mathrm{Q}$ plots and Manhattan plots. The MTAs with $-\log _{10} \mathrm{P}>$ 3 were designated as significant, and the MTAs identified in both the $\mathrm{K}+\mathrm{Q}$ and the $\mathrm{K}+\mathrm{P}$ analysis were identical. The Manhattan plots of MTAs were revealed from the $\mathrm{K}+\mathrm{Q}$ analysis, and the $\mathrm{Q}-\mathrm{Q}$ plot and MAF plot of the SNPs are shown in Fig. 3 and Additional file 5: Fig. S2, respectively. The number of significant MTAs identified in each agronomic trait were 63, 20, 17, 31, 23, 40, 24, 31, and 6 for WSR, DTH, DTM, SL, SPL, AL, LW, TKW, and SPS, respectively (Additional file 7: Table S4). The chromosomal distribution of the MTAs in each trait was diverse among the chromosomes, as shown in Additional file 7: Table S4.

\section{(a)}

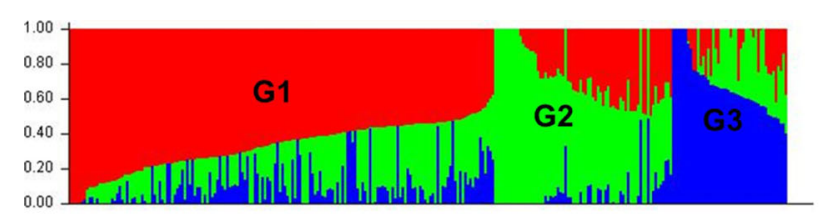

\section{(c)}

\section{(b)}
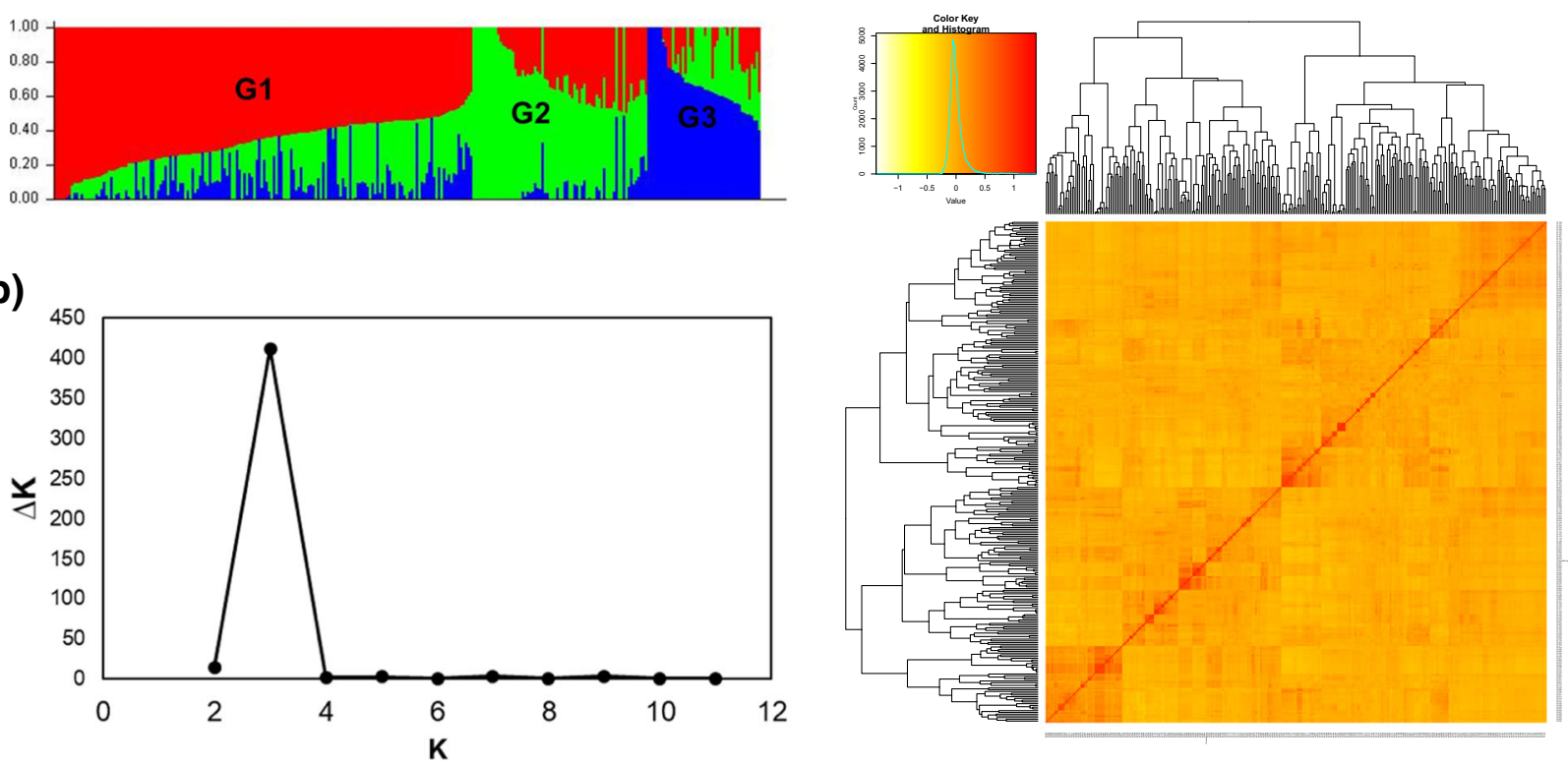

Fig. 2 Population structure and diversity analysis of 287 wheat genotypes used in this study based on 30,217 SNP markers. a Population structure based on the STRUCTURE program when $K=3$. G1, G2 and G3 represent each sub-population. $\mathbf{b} \Delta \mathrm{k}$ over three repeats of structure analysis. $\mathbf{c}$ Kinship matrix of 287 wheat genotypes based on the TASSEL5 program 

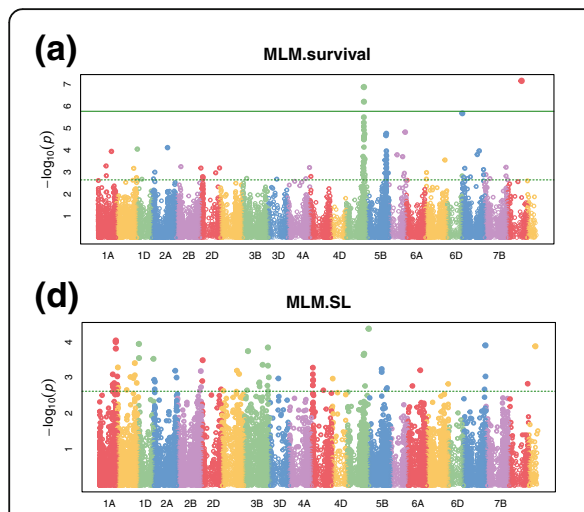

(g)

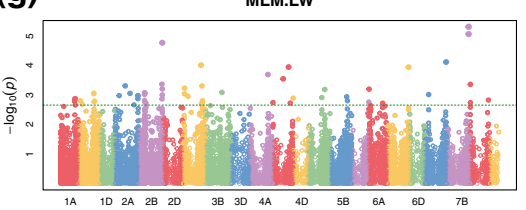

(b)

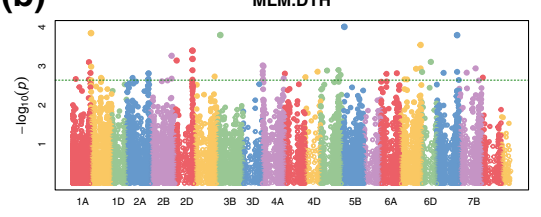

(e)

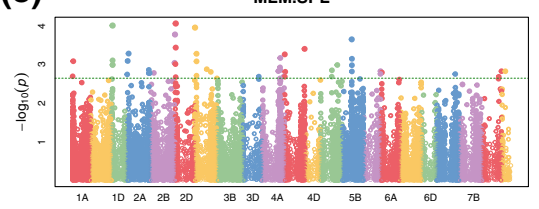

(h)

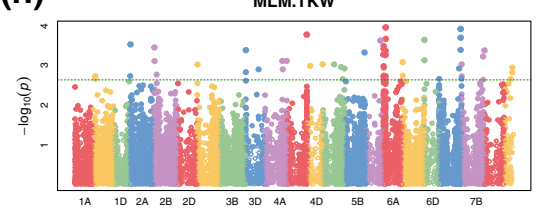

(c)

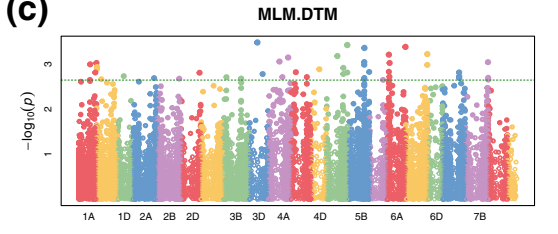

(f)

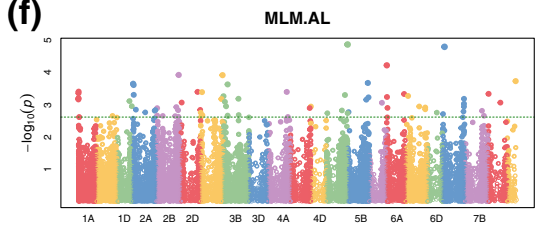

(i)

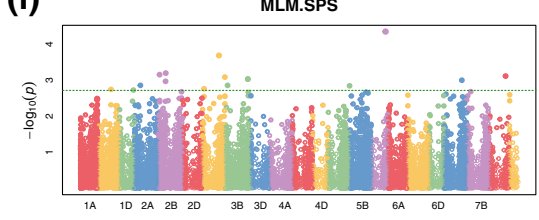

Fig. 3 Summary of genome-wide association plots for statistically significant $P$ values across 21 wheat chromosomes for SNP markers associated with nine agronomic traits. a winter survival rate, $\mathbf{b}$ days to heading, $\mathbf{c}$ days to maturity, $\mathbf{d}$ stem length, e spike length, $\mathbf{f}$ awn length, $\mathbf{g}$ liter weight, $\mathbf{h}$ thousand-kernel weight, $\mathbf{i}$ the number of seeds per spike. $\mathbf{X}$ - and $Y$-axes represent the SNP markers along each wheat chromosome and the $-\log _{10}\left(P\right.$-value), respectively. The dotted lines designate $-\log _{10} 1 \mathrm{E}^{-04}$ threshold for significant associations

The genes located within $250 \mathrm{~kb}$ of each significant locus were searched and annotated using the IWGSC Wheat RefSeq v1.0. Based on the public RNAseq data, a total of 28 genes with more than 2 -fold gene expression increase under cold treatment or with the relevant tissue-specific expression were selected (Table 2 and Additional file 6: Fig. S3). For WSR, ten genes closely located to the significant MTAs were shown to respond to cold temperatures. Most of the genes were found to be located on chromosome 5, and each one was located on chromosome 2 and 4, respectively, while two genes were located on chromosome 7. For DTH, three genes specifically expressed in the stem axis, flag leaf, or peduncle were selected and located on chromosomes 2, 6, and 7 . For DTM, nine genes highly expressed in the grain or spike were screened, among which three were located on chromosome 4, while one and five genes were located on chromosomes 5 and 6, respectively. For SL, two genes representing specific expression in the internode and peduncle were discovered, each of which was located on chromosomes 4 and 5, respectively. For SPL, one gene was found to be highly expressed in spike, which was localized on chromosome 2 . For AL, one Fbox family protein encoding gene with high expression in spikelets and awn on chromosome 2 was observed. For SPS, two genes specifically expressed in grains were discovered, located on chromosomes 2 and 3.

Real-time PCR was performed to validate the gene expression of the candidate genes. At least two genes for each trait were randomly selected and gene expression was observed. For WSR, TraesCS5A01G391700, TraesCS5A01G394900, and TraesCS5B01G454100 showed increased gene expression at $24 \mathrm{~h}, 12 \mathrm{~h}$, and $12 \mathrm{~h}$ after cold treatment (Additional file 10: Fig. S5). For DTH, TraesCS6D01G212200 and TraesCS7A01G484300 represented high expression in stem and peduncle, or only in peduncle, respectively (Fig. S6A). For DTM, TraesCS4B01G225800 and TraesCS6A01G407500 were highly expressed in spike (Fig. S6B). For SL, TraesCS4B01G052400 represented high expression in peduncle, and TraesCS5A01G320500 showed high expression in stem followed by peduncle and spike (Fig. S6c). For SPL and AL, TraesCS2D01G036800 and TraesCS2D01G064400 were highly expressed in spike and flag leaf, respectively (Fig. S6d\&e). For SPS, TraesCS2B01G087000 represented the highest expression in spike, and TraesCS01G311000 was also highly expressed in spike (Fig. S6f).

\section{The effect of alleles on agronomic traits}

To investigate the allele effect on the observed agronomic traits, the phenotypic data distribution of the wheat genotypes possessing different numbers of favorable or unfavorable alleles in different environments were compared (Fig. 4). In this study, the high winter survival rate, shorter days to heading and maturity, short stem length, spike length, short awn length, heavy liter weight, and thousand kernel weight, and large number of seeds per spike were considered favorable. In most cases, the number of favorable/unfavorable alleles had a 


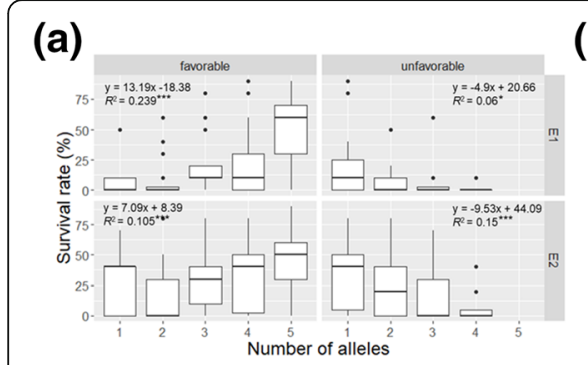

(d)

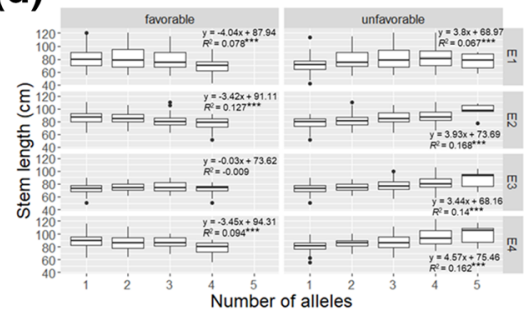

(g)

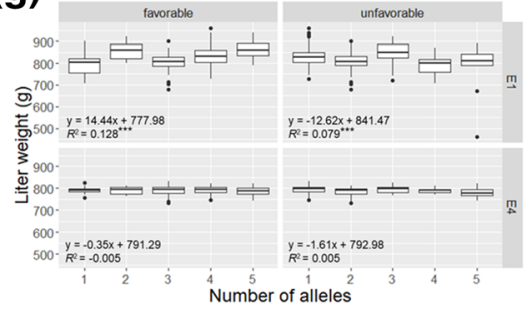

(b)

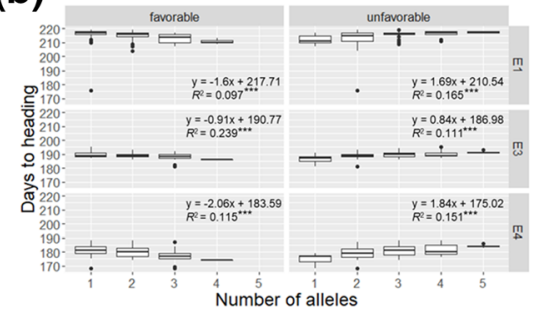

(e)

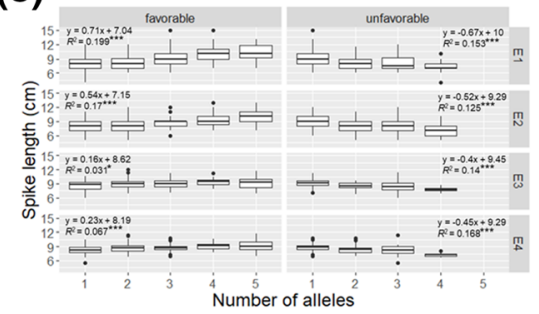

(h)

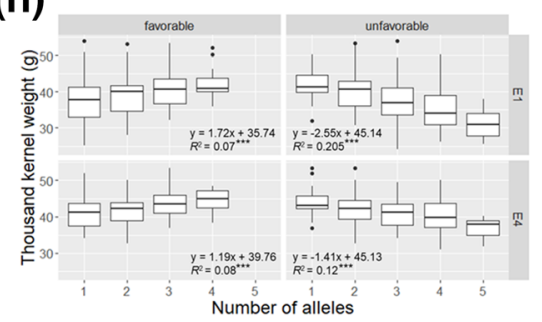

(c)

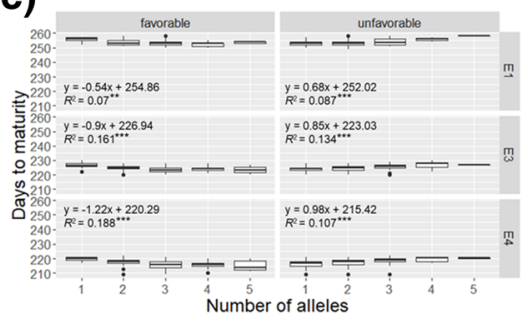

(f)

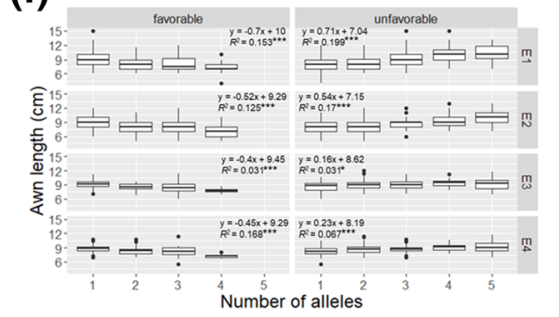

(i)

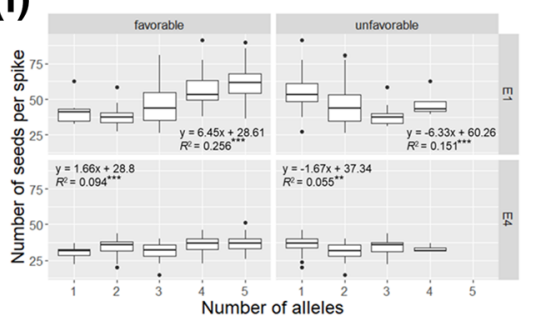

Fig. 4 The effect of alleles on the agronomic traits in different environments. The numbers on the $X$-axes indicate the number of the favorable or unfavorable alleles, while the $Y$-axes represents the phenotypic data distribution of the genotypes possessing each number of alleles. The bottom, middle and top lines in each boxplot represent 25, 50 and 75\% of the phenotypic data, respectively. E1: Deokso in 2018-2019 season, E2: Deokso in 2019-2020 season, E3: Jeonju in 2018-2019 season, E4: Jinju in 2018-2019 season. The equation of regression line between each phenotypic data and the number of alleles, and the adjusted R-square values are represented $\left.{ }^{* * *}: p<0.001,{ }^{* *}: p<0.01, *: p<0.05\right)$

significant positive or negative effect on each agronomic trait, except for the unfavorable alleles for WSR, SPL, and SPS, and the favorable alleles for DTH, SL, AL, and TKW, for which there were no wheat genotypes possessing all five unfavorable or favorable alleles. Furthermore, the allele effect for each agronomic trait was observed regardless of different environments, except for the favorable alleles in E3 for SL and the favorable/unfavorable alleles in E4 for LW.

\section{Discussion}

In this study, nine phenotypic traits of wheat were observed in two to four different environments and utilized in the GWA analysis (Additional file 2: Fig. S1). WSR was observed in four environments; however, in E3 and $\mathrm{E} 4$, there was little difference among the genotypes due to their warm climate condition, and these were therefore removed from the analysis. DTH and DTM represented large variations depending on the different environments. It was shown that they had higher values in the cold environment (E1) than in the warm environment (E4). In the Pearson's correlation analysis between each phenotypic trait (Fig. 1), DTH and DTM were highly correlated with each other, and also represented a positive correlation with SPL and SPS. This is consistent with previous studies [21, 22], which might indicate that nutrient absorption during the longer vegetative development period results in a larger spike length, and eventually a larger number of seeds per spike. A positive correlation between AL and TKW was also observed in a previous study [23], which still needs to be further studied.

The relationships among the genotypes were analyzed by three different methods: structure subpopulation analysis, PCA, and kinship matrix (Fig. 2 and Additional file 1: Table S1). All three analyses produced the same three subpopulations, which proves the reliability of the genotype analysis. It was thus shown that the genotypes were mostly divided into two subpopulations G1 and G2, while G3 was mostly composed of KU-developed lines possessing "Keumgang" as a maternal line. Since the phenotypic traits of the wheats in G3 were diverse, the focused investigation of these lines would help to identify a major QTL in a similar genetic background. 
Table 2 The significantly agronomic traits-associated markers and the putative genes concerned with the agronomic traits

\begin{tabular}{|c|c|c|c|c|c|c|}
\hline Gene ID & Annotation & Associated SNP & $\begin{array}{l}\text { SNP position on } \\
\text { chromosome }\end{array}$ & $P$-value & Alleles & MAF \\
\hline \multicolumn{7}{|l|}{ Winter survival rate } \\
\hline TraesCS2D01G032800 & $\begin{array}{l}\text { GroES-like zinc-binding alcohol } \\
\text { dehydrogenase family protein }\end{array}$ & RAC875_c38003_164 & 2D:13007354 & 0.0008 & $\underline{G} / \mathrm{A}$ & 0.21724 \\
\hline TraesCS4A01G469900 & Homeobox BEL1-like protein & Kukri_c18677_237 & $4 A: 731352373$ & 0.0008 & $\underline{A} / G$ & 0.36738 \\
\hline TraesCS5A01G359900 & Phosphatase $2 \mathrm{C}$ family protein & RAC875_c23340_2243 & 5A:561565292 & 0.0008 & $\underline{A} / G$ & 0.3723 \\
\hline TraesCS5A01G360000 & $\begin{array}{l}\text { Low temperature and salt } \\
\text { responsive protein }\end{array}$ & RAC875_c23340_2243 & $5 A: 561565292$ & 0.0008 & $\underline{A} / G$ & 0.3723 \\
\hline TraesCS5A01G391700 & Vrn-A1 & IAAV3043 & 5A:586537895 & 0.0003 & $\underline{\mathrm{A} / \mathrm{C}}$ & 0.08451 \\
\hline TraesCS5A01G394900 & UDP-glucose 6-dehydrogenase & BobWhite_c471_2245 & 5A:588454245 & 0.0002 & $\underline{A} / G$ & 0.44624 \\
\hline TraesCS5B01G397500 & $A B C$ transporter $B$ family protein & BS00065936_51 & 5B:574848793 & 0.0002 & $\underline{A} / G$ & 0.16135 \\
\hline \multirow[t]{2}{*}{ TraesCS5B01G454100 } & Protein kinase family protein & wsnp_Ku_rep_c102339_89347150 & 5B:626668012 & 0.0003 & $\underline{A} / G$ & 0.12121 \\
\hline & & wsnp_Ex_c53426_56666788 & 5B:626666488 & 0.0007 & $\underline{G} / \mathrm{A}$ & 0.15548 \\
\hline TraesCS7A01G389900 & $\begin{array}{l}\text { Extracellular ligand-gated ion } \\
\text { channel protein }\end{array}$ & BS00024617_51 & 7A:566002702 & 0.0001 & $\underline{A} / \mathrm{G}$ & 0.21715 \\
\hline TraesCS7D01G357200 & Transmembrane protein, putative & Ra_c51831_507 & 7D:460532222 & $6.71 \mathrm{E}-08$ & $\underline{G} / \mathrm{A}$ & 0.0669 \\
\hline \multicolumn{7}{|l|}{ Days to heading } \\
\hline TraesCS2D01G468900 & Starch synthase family protein & CAP11_C1070_54 & 2D:577071973 & 0.0002 & $\underline{G} / \mathrm{A}$ & 0.42179 \\
\hline TraesCS6D01G212200 & Phenylalanine ammonia-lyase & RAC875_c26887_562 & 6D:300325843 & 0.0009 & $\underline{G} / \mathrm{A}$ & 0.09666 \\
\hline TraesCS7A01G484300 & Receptor-like kinase & wsnp_Ku_c42539_50247597 & 7A:675380487 & 0.0002 & $\underline{C} / \mathrm{A}$ & 0.08772 \\
\hline \multicolumn{7}{|l|}{ Days to maturity } \\
\hline TraesCS4B01G129300 & Exostosin family protein & RAC875_C35152_372 & 4B:168404351 & 0.0009 & $\underline{A} / G$ & 0.11228 \\
\hline TraesCS4B01G225800 & Proline-rich protein & Kukri_c5502_2513 & 4B:534190263 & 0.0009 & $\underline{A} / \mathrm{C}$ & 0.31317 \\
\hline TraesCS4B01G226000 & Proline-rich protein & Kukri_c5502_2513 & 4B:534190263 & 0.0009 & $\underline{A} / \mathrm{C}$ & 0.31317 \\
\hline TraesCS5B01G356300 & $\begin{array}{l}\text { UTP--glucose-1-phosphate } \\
\text { uridylyltransferase }\end{array}$ & RAC875_c30584_75 & 5B:536161912 & 0.0004 & $\underline{C} / \mathrm{A}$ & 0.41472 \\
\hline TraesCS6A01G117600 & Homeobox protein & wsnp_BG262421A_Ta_2_2 & $6 A: 87936718$ & 0.0009 & $\underline{G} / \mathrm{A}$ & 0.15114 \\
\hline TraesCS6A01G406900 & F-box family protein & RAC875_C14887_829 & $6 A: 612287507$ & 0.0002 & $\underline{G} / \mathrm{A}$ & 0.19965 \\
\hline TraesCS6A01G407000 & F-box family protein & RAC875_C14887_829 & 6A:612287507 & 0.0002 & $\underline{G} / \mathrm{A}$ & 0.19965 \\
\hline TraesCS6A01G407500 & F-box family protein & RAC875_c14887_829 & 6A:612287507 & 0.0002 & $\underline{G} / \mathrm{A}$ & 0.19965 \\
\hline TraesCS6A01G407600 & F-box family protein & RAC875_C14887_829 & 6A:612287507 & 0.0002 & $\underline{G} / \mathrm{A}$ & 0.19965 \\
\hline \multicolumn{7}{|l|}{ Stem length } \\
\hline TraesCS4B01G052400 & MYB transcription factor & Excalibur_c36630_2194 & 4B:41020506 & 0.0007 & $\underline{G} / \mathrm{A}$ & 0.20285 \\
\hline TraesCS5A01G320500 & Myb factor & Tdurum_contig30483_167 & 5A:533701309 & 0.0004 & $\underline{A} / G$ & 0.49734 \\
\hline \multicolumn{7}{|l|}{ Spike length } \\
\hline TraesCS2D01G036800 & $\begin{array}{l}\text { Cullin-associated NEDD8- } \\
\text { dissociated protein } 1\end{array}$ & BS00062567_51 & 2D:13994909 & 0.0008 & $\underline{A} / \mathrm{G}$ & 0.14312 \\
\hline \multicolumn{7}{|l|}{ Awn length } \\
\hline TraesCS2D01G064400 & F-box family protein & Tdurum_contig42153_6232 & 2D:27609458 & 0.0009 & $\underline{G} / \mathrm{A}$ & 0.08673 \\
\hline \multicolumn{7}{|c|}{ Number of seeds per spike } \\
\hline TraesCS2B01G087000 & Response regulator 1 & BS00067781_51 & 2B:48944396 & 0.0006 & $\underline{C} / \mathrm{A}$ & 0.21617 \\
\hline TraesCS3A01G311000 & Cytokinin oxidase/dehydrogenase & RFL_Contig2616_1422 & 3A:549908041 & 0.0001 & $\mathrm{G} / \mathrm{A}$ & 0.05944 \\
\hline
\end{tabular}

The LD analysis showed that the paired markers were relatively less in D chromosomes and LD decay distance was also especially longer in D chromosomes (Fig. S4). This phenomenon was observed in a previous study
[21]. This might be due to small number of SNPs in D chromosomes in the iSelect $90 \mathrm{~K}$ chip, which had been caused by little polymorphism in D genome among wheat genotypes [16]. This is thought to be natural since 
D genome had been relatively recently incorporated into wheat genome after the mix of $\mathrm{A}$ and $\mathrm{B}$ genome [1] so that $\mathrm{D}$ genome had little chance to diverge than $\mathrm{A}$ and $\mathrm{B}$ genome. The LD decay distance was estimated to be $250 \mathrm{~kb}$, which was higher than $74.7 \mathrm{~kb}$ of [18] and lower than $393 \mathrm{~kb}$ of [24].

GWA analysis and candidate gene search for MTA identified a number of genes with functions relevant to phenotypic traits (Table 2 and Additional file 6: Fig. S3). Ten genes were identified for WSR. Six out of ten genes were located on the long arm of chromosome 5 possessing $F r-1$ and $F r-2$ locus, which controls cold tolerance [25]. An earlier GWAS study regarding cold tolerance also reported that significant MTAs were mostly located on the long arm of chromosome 5 [24]. They found polymorphisms in $C B F$ genes, an important transcription factor regulating cold response pathway [25], but MTAs regarding $C B F$ genes were not identified in this study. Instead, other putative candidate genes in chromosome 5 were suggested according to previous studies. TraesCS5A01G359900 (Phosphatase 2C family protein) belongs to the major group of protein phosphatases in plants and plays multiple roles in diverse plant metabolism. It was found that rice PP2C negatively regulates ABA signaling and enhances abiotic stress tolerance in Arabidopsis [26]. TraesCS5A01G360000 (low temperature and salt responsive protein) was extremely highly expressed under cold temperature, and the protein is conserved in diverse species; however, its function still needs to be elucidated [27]. TraesCS5A01G391700 (Vrn-A1) controls flowering time and is located in the frost Resistance-1 (Fr-1) locus, which is reported as a major QTL for cold tolerance [28], and is now thought to have pleiotropic effects in both traits [29]. TraesCS5A01G394900 (UDP-glucose 6-dehydrogenase) is involved in sucrose/polysaccharide metabolism and cell wall biosynthesis, and the overexpression of UDPglucose dehydrogenase from Larix gmelinii in Arabidopsis enhanced cold tolerance [30]. TraesCS5B01G397500 ( $A B C$ transporter $B$ family protein) is a large $A B C$ transporter family protein, which functions as a plasma membrane modifier that could activate the biotic and abiotic stress responses [31]. TraesCS5B01G454100 (protein kinase family protein) is involved in multiple plant metabolism pathways, and several protein kinases such as calcium-dependent protein kinase (CDPK), CBLinteracting protein kinase (CIPK), and mitogen-activated protein kinase (MAPK) have been identified to regulate cold tolerance in diverse plant species [32]. Putative candidate genes on other chromosomes were also suggested. TraesCS2D01G032800 (GroES-like zinc-binding alcohol dehydrogenase family protein) is an alcohol dehydrogenase family in wheat, and it was previously predicted that this gene family may play an important role in anaerobic waterlogging stress [33]. TraesCS4A01G469900 (Homeobox BEL1-like protein) is a BEL1 transcription factor that interacts with the KNOTTED protein and responds to wound response, as studied in potato [34]. TraesCS7A01G389900 (Extracellular ligand-gated ion channel protein) is not well characterized in plants, but $\mathrm{Ca}^{2+}$ ion increase inside the cell is thought to be a triggering factor of the cold response pathway [35], which makes it a putative ion channel for $\mathrm{Ca}^{2+}$ influx. TraesCS7D01G357200 (Transmembrane protein) is not characterized, but the cell membrane is the key organelle in cold perception [35] and several transmembrane proteins have been shown to control cold tolerance [36, 37].

For DTH and DTM, three and nine putative genes were suggested, respectively. DTH and DTM are highly quantitative traits and also significantly affected by growing environments. GWAS studies regarding DTH and DTM have been performed earlier by diverse research groups [21, 38, 39], but there were no overlapped candidate genes and a number of MTAs were identified. The putative candidate genes we suggest are known to have functions related to flowering and maturing, but overlapped genes with the previous studies were also not identified. TraesCS2D01G468900 (Starch synthase family protein) was highly expressed in the stem axis and peduncle; this gene controls the synthesis of amylose in starch granules, and it has been suggested that it could increase sugar mobilization at floral transition, thus being involved in florigenic signaling [40]. TraesCS6D01G212200 (Phenylalanine ammonia-lyase) is mainly involved in the lignin biosynthesis pathway, but its knock-down Brachypodium mutant revealed a late flowering phenotype [41], which might be related to flowering time in plants. TraesCS7A01G484300 (receptor-like kinase) also represented peduncle-specific gene expression. Several receptor-like kinases have been found to be involved in flowering by interacting with the main flowering regulators [42], which requires further investigation of this gene. TraesCS4B01G129300 (Exostosin family protein) was mainly expressed in the spike and anther. The function of this gene has not yet been elucidated in plants, but its expression in the pistil in tomato [43] and in the leaf at floral transition in maize [44] was observed, which implies its involvement in flowering regulation. TraesCS4B01G225800 and TraesCS4B01G226000 encode Proline-rich proteins that are specifically expressed in the spike. It has been suggested that the tomato hybrid proline-rich protein regulates flower abscission in tomato by controlling the ethylene response [45], which should be studied in wheat as well. TraesCS5B01G356300 (UTP--glucose-1phosphate uridylyltransferase) was expressed in the anther and the grain, which was proposed as a vegetative and reproductive phase rate-limiting factor in 
Arabidopsis [46]. TraesCS6A01G117600 (Homeobox protein) was expressed in developing grains, and overexpression of the WUSCHEL homeobox transcription factor OsWOX13 in rice revealed an early flowering phenotype [47]. TraesCS6A01G406900, TraesCS6A01G407000, TraesCS6A01G407500, and TraesCS6A01G407600 encode F-box family proteins that are highly expressed in the spike or grain. F-box protein is known to be involved in diverse molecular pathways, and its regulation of flowering and spike development has been observed in a number of plant species, including wheat [48].

For SL, two MYB transcription factors, TraesCS4B01G052400 and TraesCS5A01G320500, were found to be highly expressed in the peduncle and internode. Plant height of wheat is known to be mainly controlled by Reduced Height (Rht) genes through regulating the pathway of hormones, reactive oxygen species, and cell wall structure [49]. Previous studies represented multiple candidate genes that could be involved in the pathway under Rht gene, such as auxin binding protein and protein kinase [21], zinc finger protein [39], bHLH74, GDP-mannose transporter and etc. [50] and we suggest MYB transcription factors as such candidate genes. Studies regarding MYB transcription factor in wheat have mostly concentrated on diverse abiotic stress tolerance [51]. However, it has been reported that the novel MYB-like transcription factor OsMPH1 (MYB-like gene of Plant Height 1) regulates internode cell size and eventually plant height. Further studies to investigate MYB transcription factor function in plant height regulation should be performed in the future.

Two single genes were identified as having a putative role in regulating SPL and AL, respectively. Wheat spike morphology is known to be controlled by at least three loci, $\mathrm{Q}, \mathrm{C}$, and $\mathrm{S}$, which resides on chromosome $5 \mathrm{~A}, 2 \mathrm{D}$, and $3 \mathrm{D}$, respectively [52]. These genes affect various spike traits including spike length, spike morphology, grain size and shape, but since all known common wheats have $Q c S$ genotype, it is likely that there are other genes which contribute to spike morphology [53]. For awn length, three dominant awn length inhibitors, Hooded (Hd), Tipped1 (B1), and Tipped2 (B2) are known but their functions have not been characterized yet [54]. TraesCS2D01G036800 (Cullin-associated NEDD8dissociated protein 1 ) has not been widely studied, but in tomato, the suppression of this gene resulted in several phenotypic changes, including dwarfism, early flowering, and suppression of seed germination [55]. Its function in wheat, especially governing spike development, still needs to be uncovered. TraesCS2D01G064400 (F-box family protein) is involved in diverse plant metabolism as described above, but its role in awn length has not been reported. Nevertheless, another GWAS study in wheat suggested two MYB transcription factors as putative regulators of awn length [56], which might imply another uncharacterized role of MYB transcription factors.

For SPS, two genes showing high expression in grain were suggested as candidate genes. SPS is positively correlated with the number of spikelets per spike [57], and it is highly affected by biotic or abiotic stresses, which makes it difficult to find genetic factor determining its trait. Numerous MTAs or candidate genes were identified in previous studies, MTAs in chromosome 2A, 4A [58], 7B [19], and bHLH-encoding gene in chromosome 5D [39]. Our analysis revealed two genes in chromosome $2 \mathrm{~B}$ and 3A, respectively. TraesCS2B01G087000 (Response regulator 1 ) is one of the signal transduction response regulators with an unknown function. One of the response regulators, the phosphate starvation response regulator PHR1, is known as a regulator of the phosphate starvation response in plants, and it was revealed that in wheat the overexpression of Ta-PHR1-A1 increased grain yield by increasing the grain number per spike [59]. TraesCS3A01G311000 (cytokinin oxidase/dehydrogenase) regulates plant growth and development by controlling cytokinin levels in plants. Previous studies found that the gene expression levels of the cytokinin oxidase genes $T a C K X 2.1$ and $T a C K X 2.2$ were correlated with the grain number per spike [60] and TaCKK2.4-silenced wheat lines represented significantly increased grain numbers per spike [61].

The GWA analysis was performed using the BLUP values from the combined environments or from the separate environments (E1 to E4). The consistency of the MTAs was verified as shown in Additional file 7: Table S4. However, the markers for some traits such as DTM in E1, AL in E4, and LW in E4 were not shown in the combined environment. It might be because these traits are more variable depending on the environments than the other traits and also the number of the investigated accessions are different in each environment, so that significance of each marker can be different in other environments.

Real-time PCR was conducted to validate the stressresponsive or tissue-specific gene expression of the candidate genes in planta (Fig. S5 and S6). The candidate genes related to WSR were responsive to cold stress (Fig. S5), and tissue-specificity of the other genes' expressions were mostly consistent with those of the RNAseq data (Fig. S3). Especially, TraesCS2B01G087000 represented dramatically high expression in spikes, approximate 140,000 times higher than in leaves, which makes it a promise candidate gene for SPS (Fig. S6f). However, TraesCS2D01G064400 expression did not show a great difference among the tissues, which could be because awn tissue was not examined in the real-time 
PCR analysis (Fig. S6e). Further experiments will be needed to characterize the function of TraesCS2D01G064400.

The allele effect of the MTAs in each agronomic trait was observed (Fig. 4). The accumulation of the favorable alleles was positively associated with a higher WSR, shorter DTH, DTM, and SL, longer SPL and AL, higher LW, TKW, and SPS, and the accumulation of unfavorable alleles negatively affected those traits. The allele effect was observed in most of the environments, except for in E3 for SL and in E4 for LW. This might be partially due to low $H^{2}$ in LW (Table 1), which implies that these traits are highly affected by environments rather than that by genotypes.

\section{Conclusions}

In the present study, GWA analysis was performed for nine phenotypic traits of wheat in the field, and a total of 254 significant MTAs and 28 candidate genes were predicted for the seven traits, including winter survival rate, days to maturity, stem length, spike length, awn length, liter weight, and seeds per spike. Previously identified genes with known functions were observed, and several novel genes with possible uncharacterized functions in each trait were also identified. Further studies of these candidate genes and the utilization of the significant SNP markers will help to verify their molecular functions in the relevant trait and also to develop agronomic traits-improved wheats.

\section{Methods}

\section{Plant materials and phenotype measurements}

In this study, 287 wheat cultivars and advanced lines were planted at the Korea University Experimental Field Station in the Deokso area (N37.35 , E127.14 ${ }^{\circ}$, Elevation $=62 \mathrm{~m}$ ) in the 2018-2019 (E1) and 2019-2020 (E2) growing seasons. A total of 189 lines were also planted in the test field of the National Institute of Crop Science of Korea in Jeonju (E3; N35.50 ${ }^{\circ}$ E127.02 ${ }^{\circ}$, Elevation $=32$ m) and Gyeongsangnam-do Agricultural Research \& Extension Services in Jinju (E4; N35.12 ${ }^{\circ}$ E128.06 ${ }^{\circ}$, Elevation $=20 \mathrm{~m}$ ) during the 2018-2019 growing season. The field experiments were in accordance with local legislation of Korea government. Wheat accessions indicated as "Developed in KU" in "Country of origin" column are breeding lines developed in Korea University. Any accessions indicated as numbers in "IT number" column are germplasms that were kindly provided by National Agrobiodiversity Center in Rural Development Administration, Korea (Additional file 1: Table S1). The materials were planted on the 4th, 25th, and 29th of October in 2018, and harvested in June 2019, when the plants were fully matured in Deokso, Jeonju, and Jinju, respectively. For the 2019-2020 growing season in Deokso, the wheat was planted on the 17th of October, 2019 and harvested in June 2020. Five grams of seeds from each germplasm were planted in a $1.2 \mathrm{~m}$ row spaced $40 \mathrm{~cm}$ apart, and the experiment was conducted in two replications following alpha lattice design in each region.

Phenotype measurements were performed as follows. Freezing tolerance was evaluated as winter survival in integers representing the survival rate of plants per genotype, ranging from $0(0-10 \%)$ to $9(90-100 \%)$ after winter. Heading and spike maturity dates were recorded when spikes of half of each germplasm had emerged or browned, respectively. DTH and DTM were calculated by subtracting the planting date from those dates. Three plants were randomly selected and SL was measured from the ground to the bottom end of the spike. The main spikes of three plants were randomly selected and the SPL was measured from the base of the rachis to the topmost spikelet, and AL was measured. SPS was counted for three spikes in each germplasm. For LW, $200 \mathrm{~mL}$ of seed weight of each line was measured and multiplied by five. For TKW, 200 seeds of each line were counted and the weight was multiplied by five.

\section{Phenotypic data analysis}

All phenotypic data analyses were conducted using $R$ version 4.4.0 ( $\mathrm{R}$ Core Team). The mean, standard deviation, median, and coefficient of variation (CV) of quantitative data in each environment were calculated. For each accession, BLUP (best linear unbiased prediction) values across all environments were calculated using the "lme4" package [62] in $\mathrm{R}$ and the broad sense heritability $\left(H^{2}\right)$ was estimated on the basis of entry mean following $\mathrm{V}_{\mathrm{G}} /\left[\mathrm{V}_{\mathrm{G}}+\left(\mathrm{V}_{\mathrm{E}} / \mathrm{y}\right)+\mathrm{V}_{\text {error }}\right]$, where $\mathrm{V}_{\mathrm{G}}$ is the genotypic variance, $V_{E}$ is the environment variance. $V_{\text {error }}$ is the residual error variance, and $\mathrm{y}$ is the number of environments. Analysis of variance (ANOVA) was conducted by including the genotypes, environment, and genotype $x$ environment interactions as random factors. Pearson pairwise correlation was calculated for all BLUP traits using the "cor" function and the "PerformanceAnalytics" package [63] in R.

\section{Genotyping and SNP calling}

For the genotyping assay, leaves were sampled from the wheats before the booting stage in the Deokso field and stored at $-80^{\circ} \mathrm{C}$ until use. DNA was extracted from a single plant of each germplasm, according to the USDA instructor's manual using the CTAB method [64]. DNA was sent to the USDA-ARS Small Grain Genotyping Center, Fargo (https://wheat.pw.usda.gov/ GenotypingLabs/fargo) for use in the Illumina iSelect 90 K SNP Assay. SNP allele clustering and genotype calling were performed with the GenomeStudio Module Polyploid Genotyping 2.0 software (https://support.illumina. 
com/downloads/genomestudio-2-0.html). Markers with minor allele frequencies $<0.05$ and missing data $>10 \%$ were removed, giving a total of 30,218 high-quality SNPs for use in the population structure analyses and genome-wide association (GWA) analysis.

\section{Population structure and linkage disequilibrium}

The model-based Bayesian cluster analysis program STRUCTURE v2.3.4 [65] was used to infer the population structure. A total of 10,000 burn-in periods followed by 100,000 Markov chain Monte Carlo (MCMC) iterations from $\mathrm{K}=2$ to $\mathrm{K}=12$ clusters were used to identify the optimal cluster $(\mathrm{K})$. Three independent runs were generated for each $K$. An ad hoc quantity statistic, $\Delta K$, based on the rate of change in the log probability of data between successive $\mathrm{K}$ values [66] was used to predict the real number of subpopulations. Principal component analyses (PCAs) were also conducted using the TASSEL v5.2.57 [67].

The linkage disequilibrium (LD) between the pairs of 30,218 SNP marker was estimated using the TASSEL v5.2.57 with a sliding window size cut off 100 . The LD decay was analyzed as per physical distance according to [68]. Briefly, LD was estimated separately for unlinked loci and for loci on the same chromosome (unlinked $r^{2}$ and syntenic $r^{2}$, respectively). Syntenic $r^{2}$ was plotted against physical distance on chromosomes and a smooth line was drawn using the "ggplot2" package [69] in R. Unlinked $-r^{2}$ estimates were square root transformed and then beyond the parametric 95th percentile of that distribution was likely to be caused by genetic linkage. The intersection of the smooth line to syntenic $r^{2}$ with this baseline was considered as the estimate of the extent of LD in the chromosome.

\section{Genome-wide association analysis}

The BLUP of each accession was used to fit a mixed linear model (MLM) by applying the residual maximum likelihood (REML) algorithm, which was calculated to analyze the phenotypic data and estimate the mean of each individual over different environments. An association test was performed using the GAPIT package v3 [70] in R, and the MLM model utilized trait data with population structure and PCA to find marker-trait association. The analysis was performed twice for each trait by either $\mathrm{K}+\mathrm{Q}$ (kinship and population structure) or $\mathrm{K}+\mathrm{P}$ (kinship and principal component), which were compared with each other. A threshold $P$-value of 0.001 $\left(-\log _{10}(\mathrm{P})=3\right)$ was used to declare significant SNPs for GWAS results and the SNPs having $P$-value less than 0.001 were selected. Furthermore, the entire analysis was conducted in each different environment to validate the consistent performance of the marker-trait associations.
Quantile-quantile plots were drawn based on the observed and expected $\log _{10}(\mathrm{P})$ values.

To identify genes related to each agronomic trait, the high-confidence annotated genes located $\pm 250 \mathrm{~kb}$ proximal to each identified MTA (marker-trait association) were retrieved from Ensembl Plants (http://plants. ensembl.org/index.html), and the annotation of each gene followed the International Wheat Genome Sequence Consortium (IWGSC) Wheat RefSeq v1.0. Furthermore, the gene expression of the retrieved genes was observed using public RNA-seq data. For WSR-related genes, the RNAseq of 2-week cold-treatment wheat seedlings was available at the Wheat Expression Browser (http://www.wheat-expression.com/) and those genes with a more than 2 -fold increase were retrieved. For the genes concerning the rest of the agronomic traits, except for LW and TKW, tissue-specific gene expression was observed at the Wheat eFP Browser (http://bar.utoronto. ca/efp_wheat/cgi-bin/efpWeb.cgi) and the genes with TPM (Transcripts Per Million) $<5$ were removed. The heatmap of gene expression was created using the Heatmapper (http://www.heatmapper.ca/).

Furthermore, to verify allele effects on each agronomic trait, the favorable and unfavorable alleles of the five most significant MTAs in each trait were retrieved. Then, the phenotypic data distribution of the lines possessing one to five of each favorable or unfavorable allele was compared in different environments. The regression analysis between the number of favorable/unfavorable alleles and each phenotypic data was conducted using R, and the boxplots were created using the "ggplot2" package in $R$.

\section{Real-time PCR}

Gene expression of the candidate genes was observed in specific tissue or under cold temperature. RNA was extracted from specific tissues of wheat at heading stage, which were the first leaf from the ground, stem, peduncle, flag leaf, and spike. In order to observe the gene expression under cold temperature, three-leaf stage wheat seedlings grown at $25^{\circ} \mathrm{C}$ were exposed to $4{ }^{\circ} \mathrm{C}$. The RNA extraction was conducted using TRIzol (Thermo Fisher Scientific Co., USA) and cDNA was synthesized using the PrimeScript ${ }^{\text {tw }} 1$ st strand cDNA synthesis kit (Takara Bio Inc., Japan) according to the manufacturers' manuals, respectively. Each gene specific PCR primers was designed using the NCBI PrimerBLAST (https://www.ncbi.nlm.nih.gov/tools/primerblast/index.cgi? LINK_LOC=BlastHome) (Table S5). Real-time PCR was performed using BrightGreen 2X qPCR MasterMix (ABM, Canada) in a CFX-96 real-time PCR machine (Bio-Rad, USA). The Ct values obtained for each gene were normalized depending on the internal gene control, and relative gene expression levels 
were calculated using the $2^{-\Delta \Delta C T}$ method as previously described [71]. Statistical analysis was performed in $\mathrm{R}$ and differences in gene expression were evaluated with Student's t-test or one-way ANOVA (analysis of variance) followed by a Tukey post hoc test.

\section{Abbreviations}

GWA: Genome-wide association; DTH: Days to heading; DTM: Days to maturity; SL: Stem length; SPL: Spike length; AL: Awn length; LW: Liter weight; TKW: Thousand kernel weight; SPS: The number of seeds per spike; BLUP: Best linear unbiased prediction; MLM: Mixed linear model; MTA: Marker-trait association; SSR: Simple sequence repeat; RAPD: Random amplified polymorphic DNA; RFLP: Restriction fragment length polymorphism; NGS: Next-generation sequencing; SNP: Single nucleotide polymorphism; CV: Coefficient of variation; ANOVA: Analysis of variance; MCMC: Markov chain Monte Carlo; PCA: Principal component analyses; REML: Residual maximum likelihood; IWGSC: International Wheat Genome Sequence Consortium; TPM: Transcripts Per Million; CDPK: Calciumdependent protein kinase; MAPK: Mitogen-activated protein kinase

\section{Supplementary Information}

The online version contains supplementary material available at https://doi. org/10.1186/s12870-021-03180-6.

Additional file 1 : Table S1. The origin of the wheat accessions used in this study and their population structure and principal component.

Additional file 2 : Fig. S1. Frequency distribution of the observed phenotypic data in 287 wheat genotypes. (a) survival; winter survival rate (0: 0-10\% to 9: 90-100\%), (b) DTH; days to heading, (c) DTM; days to maturity, (d) SL; spike length (cm), (e) SPL; spike length (cm), (f) AL; awn length (cm), (g) LW: liter weight (g), (h) TKW; thousand-kernel weight (g), (i) SPS: Number of seeds per spike. E1: Deokso in 2018-2019 season, E2: Deokso in 2019-2020 season, E3: Jeonju in 2018-2019 season, E4: Jinju in 2018-2019 season.

Additional file $\mathbf{3}$ : Table S2. Analysis of variance (ANOVA) of the nine agronomic traits in wheat genotypes $\left({ }^{* *} p<0.0001\right)$.

Additional file 4 : Table S3. The information of SNP markers used to analyze marker-trait associations.

Additional file 5 : Fig. S2. Q-Q plot and minor allele frequency (MAF) plot of SNPS associated with nine agronomic traits. In the Q-Q plot, X-axis and $Y$-axis represent cumulative $P$-values and observed $P$-values on a - log10 scale, respectively. In the MAF plot, each SNP is shown as circles and $\mathrm{X}$-axis and $\mathrm{Y}$-axis represent the MAF and the significance of markertrait association, respectively. (a) winter survival rate, (b) days to heading, (c) days to maturity, (d) stem length, (e) spike length, (f) awn length, (g) liter weight, (h) thousand-kernel weight, (I) the number of seeds per spike.

Additional file $\mathbf{6}$ : Fig. S3. In silico gene expression of the putative agronomic traits-related genes (a) under cold temperature and (b) in diverse plant tissues. DTH; days to heading, DTM; days to maturity, SL; stem length, SPL; spike length, AL; awn length, SPS; number of seeds per spike.

Additional file $\mathbf{7}$ : Table S4. The significant marker-trait associations ( $P$ value $<0.001)$ for nine agronomic traits. he duplicated markers for each trait in different environments are marked in red.

Additional file 8 : Table S5. The information of real-time PCR primers used in this study.

Additional file 9 : Fig. S4 Scatter plot of the linkage disequilibrium (LD) decay with the critical $r^{2}$ value and the physical chromosome distance (Mbp) for the whole genome. The red dashed line shows the critical $r^{2}$ value i.e., 0.34. The pink, green, blue, and red lines indicate LD decay of $A, B, D$, and all chromosomes, respectively. The LD was estimated as pairwise squared correlations of allele frequencies $\left(r^{2}\right)$ in sliding windows of 100 loci.

Additional file 10 : Fig. S5. Relative gene expression of winter survival rate-related candidate genes under cold treatment. Error bars indicate the standard error of the mean $(n=3)$. Asterisks indicate significant difference between the expression level of control and cold-treated plants ( ${ }^{*} p$ $<0.1,{ }^{* *} p<0.01$ )

Additional file 11 : Fig. S6. Relative gene expression of candidate genes associated with (a) days to heading, (b) days to maturity, (c) stem length, (d) spike length, (e) awn length, and (f) number of seeds per spike. Error bars indicate the standard error of the mean $(n=3)$. Different letters above each bar represent statistically significant differences $(P<$ 0.05) after an analysis of variance (ANOVA) and a Tukey post hoc test.

\section{Acknowledgements}

Not applicable.

\section{Authors' contributions}

All authors contributed to the study conception and design. DNA extraction, genotyping, and data analyses were performed by WJJ. Phenotypic data management was performed by WJJ and YJL. Phenotypic data observation was performed by WJJ, YJL, CSK, and YWS. The first draft of the manuscript was written by WJJ and was subsequently reviewed and edited by YWS. All authors have read and approved the final manuscript.

\section{Funding}

This work was carried out with the support of the "Next-Generation BioGreen21 Program for Agriculture \& Technology Development (Project No. PJ015666)" Rural Development Administration, Korea Institute of Planning and Evaluation for Technology in Food, Agriculture, Forestry and Fisheries (IPET) though Agri-Bio Industry Technology Development Program, funded by Mistry of Agriculture, Food and Rural Affairs (MAFRA) (318088) and a grant from the Korea University, Republic of Korea. The funding bodies were involved in the material creation, designing the study, data analysis and writing the manuscript.

\section{Availability of data and materials}

All data generated or analyzed during this study are included in this published article and its supplementary information files.

\section{Declarations}

Ethics approval and informed consent

All the experiments on plants were carried out in accordance with guidelines of Korea University.

\section{Consent for publication}

Not applicable.

\section{Competing interests}

The authors declare that they have no competing interests.

\section{Author details}

${ }^{1}$ Department of Plant Biotechnology, Korea University, Seoul 02841, South Korea. ${ }^{2}$ Department of Biotechnology, Korea University, Seoul 02841, South Korea. ${ }^{3}$ National Institute of Crop Science, Rural Development Administration, Wanju 55365, Republic of Korea.

Received: 16 April 2021 Accepted: 11 August 2021 Published online: 13 September 2021

\section{References}

1. International Wheat Genome Sequencing Consortium. A chromosomebased draft sequence of the hexaploid bread wheat (Triticum aestivum) genome. Science. 2014;345(6194):1251788.

2. Shewry PR. Wheat. J Exp Bot. 2009;60(6):1537-53. https://doi.org/10.1093/ jxb/erp058.

3. Lee J, Chin JH, Ahn SN, Koh HJ. Brief history and perspectives on plant breeding. In: Current technologies in plant molecular breeding: Springer Netherlands; 2015. p. 1-14. https://doi.org/10.1007/978-94-017-9996-6.

4. United States Department of Agriculture National Agricultural Statistics Service. 2020;https://www.nass.usda.gov/. Accessed 12 Dec 2020. 
5. Bibi S, Dahot MU, Khan IA, Khatri A, Naqvi M. Study of genetic diversity in wheat (Triticum aestivum L.) using random amplified polymorphic DNA (RAPD) markers. Pak J Bot. 2009;41:1023-7.

6. Song Q, Shi J, Singh S, Fickus E, Costa J, Lewis J, et al. Development and mapping of microsatellite (SSR) markers in wheat. Theor Appl Genet. 2005; 110(3):550-60. https://doi.org/10.1007/s00122-004-1871-x.

7. Waldron B, Moreno-Sevilla B, Anderson JA, Stack R, Frohberg R. RFLP mapping of QTL for Fusarium head blight resistance in wheat. Crop Sci. 1999;39(3):805-11. https://doi.org/10.2135/cropsci1999.0011183X00390003 $0032 x$.

8. Mammadov J, Aggarwal R, Buyyarapu R, Kumpatla S. SNP markers and their impact on plant breeding. Int J Plant Genomics. 2012;2012:1-11. https://doi. org/10.1155/2012/728398.

9. Alqudah AM, Sallam A, Baenziger PS, Börner A. GWAS: Fast-forwarding gene identification and characterization in temperate cereals: lessons from barley - A review. J Adv Res. 2020;22:119-35.

10. Unterseer S, Bauer E, Haberer G, Seidel M, Knaak C, Ouzunova M, et al. A powerful tool for genome analysis in maize: development and evaluation of the high density 600 k SNP genotyping array. BMC Genomics. 2014;15(1): 823. https://doi.org/10.1186/1471-2164-15-823.

11. Chen $\mathrm{H}$, Xie W, He H, Yu H, Chen W, Li J, et al. A high-density SNP genotyping array for rice biology and molecular breeding. Mol Plant. 2014; 7(3):541-53. https://doi.org/10.1093/mp/sst135.

12. Bayer MM, Rapazote-Flores P, Ganal M, Hedley PE, Macaulay M, Plieske J, et al. Development and evaluation of a barley 50k iSelect SNP array. Front Plant Sci. 2017;8:1792. https://doi.org/10.3389/fpls.2017.01792.

13. Cavanagh CR, Chao S, Wang S, Huang BE, Stephen S, Kiani S, et al. Genome-wide comparative diversity uncovers multiple targets of selection for improvement in hexaploid wheat landraces and cultivars. Proc Natl Acad Sci U S A. 2013;110(20):8057-62. https://doi.org/10.1073/ pnas. 1217133110.

14. Boeven PH, Longin CFH, Leiser WL, Kollers S, Ebmeyer E, Würschum T. Genetic architecture of male floral traits required for hybrid wheat breeding. Theor Appl Genet. 2016;129(12):2343-57. https://doi.org/10.1007/s00122-01 6-2771-6.

15. Allen AM, Winfield MO, Burridge AJ, Downie RC, Benbow HR, Barker GL, et al. Characterization of a wheat breeders' array suitable for highthroughput SNP genotyping of global accessions of hexaploid bread wheat (Triticum aestivum). Plant Biotechnol J. 2017;15(3):390-401. https://doi.org/1 $0.1111 /$ pbi. 12635 .

16. Wang $\mathrm{S}$, Wong $\mathrm{D}$, Forrest $\mathrm{K}$, Allen $\mathrm{A}$, Chao $\mathrm{S}$, Huang BE, et al. Characterization of polyploid wheat genomic diversity using a high-density 90,000 single nucleotide polymorphism array. Plant Biotechnol J. 2014;12(6): 787-96. https://doi.org/10.1111/pbi.12183.

17. Yan X, Zhao L, Ren Y, Dong Z, Cui D, Chen F. Genome-wide association study revealed that the TaGW8 gene was associated with kernel size in Chinese bread wheat. Sci Rep. 2019;9(1):2702. https://doi.org/10.1038/s41 598-019-38570-2.

18. Li F, Wen W, Liu J, Zhang Y, Cao S, He Z, et al. Genetic architecture of grain yield in bread wheat based on genome-wide association studies. BMC Plant Biol. 2019;19(1):168. https://doi.org/10.1186/s12870-019-1781-3.

19. Liu J, Xu Z, Fan X, Zhou Q, Cao J, Wang F, et al. A genome-wide association study of wheat spike related traits in China. Front Plant Sci. 2018;9:1584. https://doi.org/10.3389/fpls.2018.01584.

20. Appels R, Eversole K, Stein N, Feuillet C, Keller B, Rogers J, et al. Shifting the limits in wheat research and breeding using a fully annotated reference genome. Science. 2018;361(6403).

21. Sheoran S, Jaiswal S, Kumar D, Raghav N, Sharma R, Pawar S, et al. Uncovering genomic regions associated with 36 agro-morphological traits in Indian spring wheat using GWAS. Front Plant Sci. 2019;10:527. https://doi. org/10.3389/fpls.2019.00527.

22. Mwadzingeni L, Shimelis H, Tesfay S, Tsilo TJ. Screening of bread wheat genotypes for drought tolerance using phenotypic and proline analyses. Front Plant Sci. 2016;7:1276

23. Ntakirutimana F, Xiao B, Xie W, Zhang J, Zhang Z, Wang N, et al. Potential effects of awn length variation on seed yield and components, seed dispersal and germination performance in Siberian wildrye (Elymus sibiricus L.). Plants. 2019:8:561.

24. Zhao Y, Li J, Zhao R, Xu K, Xiao Y, Zhang S, et al. Genome-wide association study reveals the genetic basis of cold tolerance in wheat. Mol Breed. 2020; 40(4):36. https://doi.org/10.1007/s11032-020-01115-x.
25. Vágúffalvi A, Galiba G, Cattivelli L, Dubcovsky J. The cold-regulated transcriptional activator $\mathrm{Cbf} 3$ is linked to the frost-tolerance locus Fr-A2 on wheat chromosome 5A. Mol Genet Genomics. 2003;269(1):60-7. https://doi. org/10.1007/s00438-003-0806-6.

26. Singh A, Jha SK, Bagri J, Pandey GK. ABA inducible rice protein phosphatase $2 \mathrm{C}$ confers ABA insensitivity and abiotic stress tolerance in Arabidopsis. PLoS One. 2015;10(4):e0125168. https://doi.org/10.1371/journal.pone.0125168.

27. Nylander M, Heino P, Helenius E, Palva ET, Ronne H, Welin BV. The lowtemperature-and salt-induced RCI2A gene of Arabidopsis complements the sodium sensitivity caused by a deletion of the homologous yeast gene SNA1. Plant Mol Biol. 2001;45(3):341-52. https://doi.org/10.1023/A:1006451 914231

28. Tóth B, Galiba G, Fehér E, Sutka J, Snape JW. Mapping genes affecting flowering time and frost resistance on chromosome $5 \mathrm{~b}$ of wheat. Theor Appl Genet. 2003;107(3):509-14. https://doi.org/10.1007/s00122-003-1275-3.

29. Würschum T, Longin CFH, Hahn V, Tucker MR, Leiser WL. Copy number variations of CBF genes at the Fr-A2 locus are essential components of winter hardiness in wheat. Plant J. 2017;89(4):764-73. https://doi.org/1 $0.1111 /$ tpj.13424.

30. Li N, Chen L, Li X, Li Q, Zhang W, Takechi K, et al. Overexpression of UDPglucose dehydrogenase from Larix gmelinii enhances growth and cold tolerance in transgenic Arabidopsis thaliana. Biol Plant. 2017;61(1):95-105. https://doi.org/10.1007/s10535-016-0657-8.

31. Deppe JP, Rabbat R, Hörtensteiner S, Keller B, Martinoia E, Lopéz-Marqués RL. The wheat $A B C$ transporter $L r 34$ modifies the lipid environment at the plasma membrane. J Biol Chem. 2018;293(48):18667-79. https://doi.org/10.1 074/jbc.RA118.002532.

32. Guo X, Liu D, Chong K. Cold signaling in plants: insights into mechanisms and regulation. J Integr Plant Biol. 2018;60(9):745-56. https://doi.org/1 $0.1111 /$ jipb.12706

33. Shen C, Yuan J, Ou X. Alcohol dehydrogenase (ADH) genes family in wheat (Triticum aestivum): genome-wide identification, characterization, phylogenetic relationship and expression patterns. Preprint Res Square. 2020. https://doi.org/10.21203/rs.3.rs-60428/v1.

34. Sharma P, Lin T, Grandellis C, Yu M, Hannapel DJ. The BEL1-like family of transcription factors in potato. J Exp Bot. 2014;65(2):709-23. https://doi.org/1 $0.1093 / \mathrm{jxb} / \mathrm{ert} 432$.

35. Miura K, Furumoto T. Cold signaling and cold response in plants. Int J Mol Sci. 2013;14(3):2312-37.

36. Su C, Chen K, Ding Q, Mou Y, Yang R, Zhao M, et al. Proteomic analysis of the function of a novel cold-regulated multispanning transmembrane protein COR413-PM1 in Arabidopsis. Int J Mol Sci. 2018;19(9):2572. https:// doi.org/10.3390/ijms19092572.

37. Zhou A, Liu E, Li H, Li Y, Feng S, Gong S, et al. PsCor413pm2, a plasma membrane-localized, cold-regulated protein from Phlox subulata, confers low temperature tolerance in Arabidopsis. Int J Mol Sci. 2018;19(9):2579. https://doi.org/10.3390/ijms19092579.

38. Jamil M, Ali A, Gul A, Ghafoor A, Napar AA, Ibrahim AMH, et al. Genomewide association studies of seven agronomic traits under two sowing conditions in bread wheat. BMC Plant Biol. 2019;19(1):149. https://doi.org/1 $0.1186 / s 12870-019-1754-6$

39. Gahlaut V, Jaiswal V, Singh S, Balyan HS, Gupta PK. Multi-locus genome wide association mapping for yield and its contributing traits in hexaploid wheat under different water regimes. Sci Rep. 2019;9(1):19486. https://doi. org/10.1038/s41598-019-55520-0.

40. Ortiz-Marchena Ml, Albi T, Lucas-Reina E, Said FE, Romero-Campero FJ, Cano $B$, et al. Photoperiodic control of carbon distribution during the floral transition in Arabidopsis. Plant Cell. 2014;26(2):565-84. https://doi.org/10.11 05/tpc.114.122721.

41. Cass CL, Peraldi A, Dowd PF, Mottiar Y, Santoro N, Karlen SD, et al. Effects of PHENYLALANINE AMMONIA LYASE (PAL) knockdown on cell wall composition biomass digestibility, and biotic and abiotic stress responses in Brachypodium. J Exp Bot. 2015;66(14):4317-35. https://doi.org/10.1093/jxb/ erv269.

42. Wang L, Yang T, Lin Q, Wang B, Li X, Luan S, et al. Receptor kinase FERONIA regulates flowering time in Arabidopsis. BMC Plant Biol. 2020;20(1):26. https://doi.org/10.1186/s12870-019-2223-y.

43. Ezura K, Ji-Seong K, Mori K, Suzuki Y, Kuhara S, Ariizumi T, et al. Genomewide identification of pistil-specific genes expressed during fruit set initiation in tomato (Solanum lycopersicum). PLoS One. 2017;12(7):e0180003. https://doi.org/10.1371/journal.pone.0180003. 
44. Alter P, Bircheneder S, Zhou LZ, Schlüter U, Gahrtz M, Sonnewald U, et al. Flowering time-regulated genes in maize include the transcription factor ZmMADS1. Plant Physiol. 2016;172(1):389-404. https://doi.org/10.1104/pp.16. 00285.

45. Sundaresan S, Philosoph-Hadas S, Ma C, Jiang CZ, Riov J, Mugasimangalam $R$, et al. The tomato hybrid proline-rich protein regulates the abscission zone competence to respond to ethylene signals. Hortic Res. 2018;5(1):28. https://doi.org/10.1038/s41438-018-0033-2.

46. Park JI, Ishimizu T, Suwabe K, Sudo K, Masuko H, Hakozaki H, et al. UDPglucose pyrophosphorylase is rate limiting in vegetative and reproductive phases in Arabidopsis thaliana. Plant Cell Physiol. 2010;51(6):981-96. https:// doi.org/10.1093/pcp/pcq057.

47. Minh-Thu PT, Kim JS, Chae S, Jun KM, Lee GS, Kim DE, et al. A WUSCHEL homeobox transcription factor, OsWOX13, enhances drought tolerance and triggers early flowering in rice. Mol Cells. 2018;41(8):781-98. https://doi.org/1 0.14348/molcells.2018.0203

48. Hong MJ, Kim DY, Kang SY, Kim DS, Kim JB, Seo YW. Wheat F-box protein recruits proteins and regulates their abundance during wheat spike development. Mol Biol Rep. 2012;39(10):9681-96. https://doi.org/10.1007/s11 033-012-1833-3.

49. Chai S, Yao Q, Zhang X, Xiao X, Fan X, Zeng J, et al. The semi-dwarfing gene Rht-dp from dwarf polish wheat (Triticum polonicum L.) is the "Green Revolution" gene Rht-B1b. BMC Genom. 2021;1-15.

50. Muhammad A, Li J, Hu W, Yu J, Khan SU, Khan MHU, et al. Uncovering genomic regions controlling plant architectural traits in hexaploid wheat using different GWAS models. Sci Rep. 2021;11(1):1-14.

51. Zhao $Y$, Cheng $X$, Liu X, Wu H, Bi H, Xu H. The wheat MYB transcription factor TaMYB31 is involved in drought stress responses in Arabidopsis. Front Plant Sci. 2018;9:1426. https://doi.org/10.3389/fpls.2018.01426.

52. Wolde GM, Trautewig C, Mascher M, Schnurbusch T. Genetic insights into morphometric inflorescence traits of wheat. Theor Appl Genet. 2019;132(6): 1661-76. https://doi.org/10.1007/s00122-019-03305-4

53. Zhai H, Feng Z, Li J, Liu X, Xiao S, Ni Z, et al. QTL analysis of spike morphological traits and plant height in winter wheat (Triticum aestivum L.) using a high-density SNP and SSR-based linkage map. Front Plant Sci. 2016; 7:1617. https://doi.org/10.3389/fpls.2016.01617.

54. Niu J, Zheng S, Shi X, Si Y, Tian S, He Y, et al. Fine mapping and characterization of the awn inhibitor B1 locus in common wheat (Triticum aestivum L.). Crop J. 2020;8(4):613-22.

55. Cheng W, Yin S, Tu Y, Mei H, Wang Y, Yang Y. SICAND1, encoding cullinassociated Nedd8-dissociated protein 1, regulates plant height, flowering time, seed germination, and root architecture in tomato. Plant Mol Biol. 2020;102(4):537-51. https://doi.org/10.1007/s11103-020-00963-7.

56. Bhatta M, Morgounov A, Belamkar V, Baenziger PS. Genome-wide association study reveals novel genomic regions for grain yield and yieldrelated traits in drought-stressed synthetic hexaploid wheat. Int J Mol Sci. 2018;19(10):3011. https://doi.org/10.3390/ijms19103011.

57. Deng M, Wu F, Zhou W, Li J, Shi H, Wang Z, et al. Mapping of QTL for total spikelet number per spike on chromosome 2D in wheat using a highdensity genetic map. Genet Mol Biol. 2019;42:603-10.

58. Basile SML, Ramírez IA, Crescente JM, Conde MB, Demichelis M, Abbate P, et al. Haplotype block analysis of an Argentinean hexaploid wheat collection and GWAS for yield components and adaptation. BMC Plant Biol. 2019;19(1):1-16.

59. Wang J, Sun J, Miao J, Guo J, Shi Z, He M, et al. A phosphate starvation response regulator Ta-PHR1 is involved in phosphate signalling and increases grain yield in wheat. Ann Bot. 2013;111(6):1139-53. https://doi. org/10.1093/aob/mct080.

60. Zhang J, Liu W, Yang X, Gao A, Li X, Wu X, et al. Isolation and characterization of two putative cytokinin oxidase genes related to grain number per spike phenotype in wheat. Mol Biol Rep. 2011;38(4):2337-47. https://doi.org/10.1007/s11033-010-0367-9.

61. Li Y, Song G, Gao J, Zhang S, Zhang R, Li W, et al. Enhancement of grain number per spike by RNA interference of cytokinin oxidase 2 gene in bread wheat. Hereditas. 2018;155(1):33. https://doi.org/10.1186/s41065-018-0071-7.

62. Bates $D$, Mächler $M$, Bolker B, Walker S. Fitting linear mixed-effects models using Ime4. J Stat Softw. 2015;67(1):1-48. https://doi.org/10.18637/jss.v067. i01.

63. Peterson BG, Carl P, Boudt K, Bennett R, Ulrich J, Zivot E, Cornilly D, Hung E, Lestel M, Balkissoon K, Wuertz D, Christidis AA, Martin RD, Zhou ZZ, Shea
JM. Econometric tools for performance and risk analysis. R package version. 2014;1(3).

64. Doyle J. DNA protocols for plants. In: Hewitt GM, Johnston, AWB, Young, JPW (ed) Molecular techniques in taxonomy. Berlin: Springer; 1991. p 283293.

65. Evanno G, Regnaut S, Goudet J. Detecting the number of clusters of individuals using the software STRUCTURE: a simulation study. Mol Ecol. 2005;14(8):2611-20. https://doi.org/10.1111/j.1365-294X.2005.02553.X.

66. Hubisz MJ, Falush D, Stephens M, Pritchard JK. Inferring weak population structure with the assistance of sample group information. Mol Ecol Resour. 2009:9(5):1322-32. https://doi.org/10.1111/j.1755-0998.2009.02591.x.

67. Bradbury PJ, Zhang Z, Kroon DE, Casstevens TM, Ramdoss Y, Buckler ES. TASSEL: software for association mapping of complex traits in diverse samples. Bioinformatics. 2007;23(19):2633-5. https://doi.org/10.1093/ bioinformatics/btm308.

68. Breseghello F, Sorrells ME. Association mapping of kernel size and milling quality in wheat (Triticum aestivum L.) cultivars. Genetics. 2006;172(2):116577. https://doi.org/10.1534/genetics.105.044586.

69. Wickham H. ggplot2: elegant graphics for data analysis. New York: SpringerVerlag; 2016. ISBN 978-3-319-24277-4, https://ggplot2.tidyverse.org

70. Lipka AE, Tian F, Wang Q, Peiffer J, Li M, Bradbury PJ, et al. GAPIT: genome association and prediction integrated tool. Bioinformatics. 2012;28(18):23979. https://doi.org/10.1093/bioinformatics/bts444.

71. Livak KJ, Schmittgen TD. Analysis of relative gene expression data using real-time quantitative PCR and the 2(-Delta Delta C(T)) method. Methods. 2001;25(4):402-8. https://doi.org/10.1006/meth.2001.1262.

\section{Publisher's Note}

Springer Nature remains neutral with regard to jurisdictional claims in published maps and institutional affiliations.

Ready to submit your research? Choose BMC and benefit from:

- fast, convenient online submission

- thorough peer review by experienced researchers in your field

- rapid publication on acceptance

- support for research data, including large and complex data types

- gold Open Access which fosters wider collaboration and increased citations

- maximum visibility for your research: over $100 \mathrm{M}$ website views per year

At $\mathrm{BMC}$, research is always in progress.

Learn more biomedcentral.com/submissions 